Article

\title{
Mosaicplasty versus Matrix-Assisted Autologous Chondrocyte Transplantation for Knee Cartilage Defects: A Long-Term Clinical and Imaging Evaluation
}

\author{
Stefano Zaffagnini ${ }^{1}{ }^{(\mathbb{D}}$, Angelo Boffa ${ }^{1, *} \mathbb{D}$, Luca Andriolo $\left.{ }^{1}{ }^{(}\right)$, Davide Reale ${ }^{1}$, Maurizio Busacca ${ }^{2}$, \\ Alessandro Di Martino ${ }^{1}$ and Giuseppe Filardo ${ }^{3,4}$ \\ 1 2nd Orthopaedic and Traumatologic Clinic, IRCCS Istituto Ortopedico Rizzoli, 40136 Bologna, Italy; \\ stefano.zaffagnini@unibo.it (S.Z.); lucas.andriolo@gmail.com (L.A.); dawidh.reale@gmail.com (D.R.); \\ aledimartino75@gmail.com (A.D.M.) \\ 2 Reference Center of Radiology in Research; IRCCS Istituto Ortopedico Rizzoli, 40136 Bologna, Italy; \\ maurizio.busacca@ior.it \\ 3 Applied and Translational Research (ATR) Center, IRCCS Istituto Ortopedico Rizzoli, 40136 Bologna, Italy; \\ ortho@gfilardo.com \\ 4 Orthopaedic and Traumatology Unit, Ospedale Regionale di Lugano, EOC, 6900 Lugano, Switzerland \\ * Correspondence: angeloboffa@libero.it; Tel.: +39-051-636-6567
}

Received: 26 May 2020; Accepted: 1 July 2020; Published: 3 July 2020

\begin{abstract}
Different surgical procedures have been proposed over the past few years to treat cartilage lesions. The aim of this study was to compare mosaicplasty and matrix-assisted autologous chondrocyte transplantation (MACT) at long-term follow-up. Forty-three patients were included: 20 mosaicplasty and 23 MACT. Patients were evaluated before and 12 years after surgery with the International Knee Documentation Committee (IKDC) subjective and objective scores for symptoms and function, and with the Tegner score for activity level. Magnetic Resonance Imaging (MRI) was used to evaluate repair tissue with the MOCART 2.0 score. Mosaicplasty and MACT showed good clinical and MRI results (IKDC subjective score $75.3 \pm 21.8$ and $81.8 \pm 13.0$, both $p<0.0005$ ). Mosaicplasty presented a $10 \%$ reoperation rate and a $25 \%$ overall failure rate, while no failures were documented in MACT $(\mathrm{p}=0.016)$. While size did not influence the results in the MACT group, mosaicplasty presented lower IKDC objective and Tegner scores in lesions bigger than $2 \mathrm{~cm}^{2}(p=0.031$ and $p=0.014$, respectively). Mosaicplasty and MACT presented both satisfactory clinical and MRI results at long-term follow-up. However, for larger lesions, MACT presented better subjective and objective outcomes, as well as less failures, which should be considered when choosing the most suitable treatment for patients affected by knee cartilage lesions.
\end{abstract}

Keywords: mosaicplasty; MACT; ACI; scaffold; osteochondral autologous transplantation; OAT; cartilage; knee

\section{Introduction}

Articular cartilage lesions of the knee are a common issue, often affecting a young population and causing pain and functional impairment, with consequent high social impact [1,2]. Due to the limited cartilage healing potential and the difficulty to restore complex biomechanical features, chondral defects remain a challenging problem [3]. Thus, to avoid their deleterious consequences, such as the risk of further cartilage loss and osteoarthritis $(\mathrm{OA})$ development, numerous surgical procedures have been proposed over the years to restore the articular surface with hyaline-like, durable repair tissue, 
from reconstructive techniques to the more ambitious regenerative strategies [4-7]. For these surgical approaches, the first procedures described were osteochondral autologous transplantation (OAT) and autologous chondrocyte implantation $(\mathrm{ACI})$, respectively $[8,9]$. These techniques demonstrated promising results up to long-term follow-up, but they also showed several drawbacks, such as significant donor site morbidity for OAT [10], and the risk of graft hypertrophy for ACI [11]. Moreover, both procedures were doomed by the complexity and morbidity of the surgical procedure, requiring an arthrotomy, and thus producing a higher risk of joint stiffness and arthrofibrosis [12,13].

Therefore, these approaches have been further developed to overcome the aforementioned limitations. On the one hand, the introduction of the mosaicplasty technique involved the use of multiple autologous osteochondral plugs of smaller diameter compared to OAT, thus causing lower morbidity, transferred from lower weight-bearing areas to the cartilage defect [14]. On the other hand, matrix-assisted autologous chondrocyte transplantation (MACT) was introduced to overcome ACI drawbacks thanks to the use of different types of scaffolds for chondrocyte culture and the direct transplantation of a bioengineered tissue, a more manageable and stronger implant for an easier and more stable positioning of the cell-scaffold construct [15]. Moreover, both options can be performed through an arthroscopic approach, allowing to reduce patient's morbidity, surgical time, recovery, and complications related to open surgery $[14,16]$. Both techniques showed promising short-term results, later confirmed by studies at long-term follow-up [17,18]. Mosaicplasty was suggested to provide better clinical results compared to MACT at short-term [19], but data on long-term comparison between these two techniques are still lacking.

The aim of this study was to compare the clinical outcomes and the quality of repair tissue provided by mosaicplasty and MACT for the treatment of knee cartilage defects at long-term follow-up.

\section{Materials and Methods}

\subsection{Patient Selection}

All patients undergoing a cartilage repair procedure were prospectively followed, and clinical outcomes were collected in an institutional database, approved by the Hospital Ethics Committee and Internal Review Board of the Rizzoli Orthopedic Institute, Bologna, Italy (prot. gen. n. 39667). Informed consent of all patients was obtained. Surgical indications for these procedures were as follows: focal cartilage knee defects graded III-IV according to International Cartilage Regeneration \& Joint Preservation Society (ICRS) classification in patients complaining of clinical symptoms (pain, swelling, locking, and giving way) after failure of conservative treatments. Contra-indications for surgery were untreated limb misalignment or knee instability, diffuse arthritis or bipolar ("kissing") lesions, and other general medical conditions such as infectious, tumor, metabolic, rheumatic, and inflammatory diseases. A definitive diagnosis of chondral lesion and sizing was performed during the arthroscopic procedure. Patients who presented with an anterior cruciate (ACL) lesion at the time of surgery underwent the combined ACL reconstruction in the same surgical session with cartilage harvesting.

A statistician, blinded to the treatment outcome, extracted two homogeneous groups of patients from the general database treated with mosaicplasty or MACT. These groups were comparable both in terms of patient demographics and cartilage lesion features. In detail, male or female patients were included, aged between 18 and 40 years, with body mass index (BMI) between 18.5 and 30, treated for lesions involving only femoral condyles (excluding trochlea and tibial plateau), with defect size between 1.0 and $3.0 \mathrm{~cm}^{2}$, traumatic or degenerative etiology (excluding osteochondritis dissecans lesions), and evaluated up to a minimum 10-year follow-up. According to these criteria, 43 patients were included in the study: 20 mosaicplasty and 23 MACT. The specific characteristics of the two groups are reported in Table 1. Statistical analysis confirmed that the two treatment groups were homogeneous with regard to gender, age, BMI, activity level, defect size and location, etiology, combined and previous surgery. 
Table 1. Comparison of patient and lesion characteristics in the two groups.

\begin{tabular}{cccc}
\hline Baseline Characteristics & Mosaicplasty & MACT & Comparison \\
\hline Patients, $\mathrm{n}$ (Men/Women) & $20(15 / 5)$ & $23(18 / 5)$ & $\mathrm{NS}$ \\
Age, y mean (SD) & $28.7(7.3)$ & $29.1(5.9)$ & $\mathrm{NS}$ \\
BMI, mean (SD) & $23.4(2.6)$ & $24.0(2.4)$ & $\mathrm{NS}$ \\
Sport activity, $\mathrm{n}(\%)$ & & & \\
Non-competitive level & $11(55.0 \%)$ & $12(52.2 \%)$ & $\mathrm{NS}$ \\
Competitive level & $9(45.0 \%)$ & $11(47.8 \%)$ & \\
Etiology, $\mathrm{n}(\%)$ & & & \\
Traumatic & $5(25.0 \%)$ & $12(52.2 \%)$ & $\mathrm{NS}$ \\
Degenerative & $15(75.0 \%)$ & $11(47.8 \%)$ & \\
Combined surgery, $\mathrm{n}(\%)$ & $15(75.0 \%)$ & $15(65.2 \%)$ & \\
ACL reconstruction, $n$ & $9(45.0 \%)$ & $12(52.2 \%)$ & $\mathrm{NS}$ \\
Meniscal treatment, $n$ & $11(55.0 \%)$ & $10(43.5 \%)$ & \\
Previous surgery, $\%$ & $8(40.0 \%)$ & $11(47.8 \%)$ & \\
ACL reconstruction, $n$ & $4(20.0 \%)$ & $3(13.0 \%)$ & NS \\
Meniscal treatment, $n$ & $3(15.0 \%)$ & $4(17.4 \%)$ & \\
Cartilage treatment, $\mathrm{n}$ & $1(5.0 \%)$ & $4(17.4 \%)$ & \\
Defect size, cm ${ }^{2}(\mathrm{SD})$ & $2.0(0.6)$ & $2.0(0.6)$ & NS \\
Location, $\mathrm{n}(\%)$ & & & \\
Medial Femoral Condyle & $12(60.0 \%)$ & $12(52.2 \%)$ & NS \\
Lateral Femoral Condyle & $8(40.0 \%)$ & $11(47.8 \%)$ & \\
\hline
\end{tabular}

Statistical analysis showed no significant differences between the two groups. ACL, anterior cruciate ligament; BMI, body mass index; MACT, matrix-assisted autologous chondrocyte transplantation; NS, not significant; SD, standard deviation; $y$, years.

\subsection{Surgical Techniques and Rehabilitation Protocols}

Arthroscopic mosaicplasty was performed in one step using the Autogenous Osteochondral Grafting System (Smith \& Nephew, London, UK) surgical instrumentation, as previously described [20]. In brief, damaged cartilaginous and fibrous tissue was excised, and the lesion was then measured for size and location. Recipient $15 \mathrm{~mm}$ deep holes were made perpendicular to the cartilage surface. After preparing the defect area, osteochondral grafts were harvested. The donor site was preferentially the superolateral ridge of the femoral condyle, whereas the superomedial ridge was used only when four grafts were necessary. Tubular chisels were used to harvest the graft and then, with a smooth cannula, the grafts were delivered into the defect. One plug was used in 4 patients, 2 plugs in 9 patients, 3 plugs in 5 patients, and 4 plugs in 2 patients. The stability of the plugs was tested by cyclic bending of the knee while grafts were visualized.

Arthroscopic MACT was performed in two steps as previously described [21]. In brief, the first procedure consisted of an arthroscopic biopsy of healthy cartilage, sent for chondrocyte cell culture and subsequent seeding onto a hyaluronic acid-based scaffold (Hyaff 11, Fidia Advanced Biopolymers Laboratories, Padova, Italy) to obtain the bioengineered tissue Hyalograft C (Fidia Advanced Biopolymers Laboratories, Padova, Italy). After 6 weeks, the second step was performed, and the bioengineered tissue was arthroscopically implanted through cannulated devices. Because of the physical adhesive characteristics of the graft, no fibrin glue or sutures were used to fix the implant. Under arthroscopic control, the stability of implanted patches was evaluated during cyclic bending of the knee.

Postoperative rehabilitation protocols were comparable for both treatments. Postoperative management focused on early mobilization to facilitate faster resolution of swelling, promote healing and joint nutrition, and prevent adhesions. Passive knee range of motion (ROM) exercises on a continuous passive motion $(\mathrm{CPM})$ machine $\left(0^{\circ}-30^{\circ}\right)$ and static quadriceps exercises were started few days after surgery. Usually, $90^{\circ}$ of knee flexion was reached within 4 weeks and full ROM within 8 weeks after surgery. Toe-touch ambulation with crutches and braces in full extension was allowed the third or fourth week and was usually completed within 6 to 8 weeks after surgery. Progressive 
recovery of functional daily activities and muscle strength were performed, with particular care during exercises in open kinetic chain, which were allowed only after 12 weeks. In the mosaicplasty group, full athletic activity was permitted after 4 months and contact and traumatic sports were allowed after 6 months. In the MACT group, high-impact activities were discouraged until 10 to 12 months after implantation.

\subsection{Clinical and Radiological Evaluation}

Patients were evaluated before surgery and prospectively for a mean of 12 years of follow-up (140.2 \pm 15.1 months, range 120-168 months) with the International Knee Documentation Committee (IKDC) subjective and objective scores for the evaluation of knee symptoms and function, and with the Tegner score for activity level. Effusion and passive motion deficit were used to determine the final functional grade of the knee (A-normal, B-nearly normal, C-abnormal, or D—severely abnormal). Failures were also recorded: the procedures were considered to have failed if the patient needed a reoperation because of symptoms related to the primary defect. For these patients, the scores of the latest follow-up available before reoperation were carried forward at the final follow-up. Besides surgical failures, patients without a clinically significant improvement (10 IKDC subjective points compared with the baseline evaluation, as previously described [22]) were considered to be a clinical failure.

Magnetic Resonance Imaging (MRI) was used to evaluate the repair tissue in 30 knees (15 of the mosaicplasty group and 15 of the MACT group) at long-term follow-up. MRI evaluation was performed using a 1.5-T superconducting magnet (General Electric Co, Fairfield, Connecticut) with a dedicated phased array ( 8 channels) HD knee coil. The following sequences were used for graft evaluation: sagittal fast spin echo proton density weighted with fat saturation (TR 3500, TE 22, FOV 16, slice thickness $3 \mathrm{~mm}$, Matr $320 \times 256$ ); sagittal T2 MAP (TR 1000, echoes 8 FOV 16, Th. $3 \mathrm{~mm}$ Matr $320 \times 224$ ); sagittal 3D "Cube" proton density weighted (TR 2500, TE 30, FOV 20, slice thickness $0.8 \mathrm{~mm}$ Matr $288 \times 288$ ); coronal fast spin echo proton density weighted with fat saturation (TR 2600, TE 40, FOV 16, slice thickness $4 \mathrm{~mm}$, Matr $320 \times 224$ ); axial fast spin echo proton density weighted with fat saturation (TR 2600, TE 40, FOV 16, slice thickness $4 \mathrm{~mm}$, Matr $320 \times 224$ ). The magnetic resonance observation of cartilage repair tissue (MOCART) 2.0 scoring system was applied for graft evaluation, which considers seven variables to describe morphology and signal intensity of the repair tissue [23]. All imaging evaluations were performed by an orthopedic surgeon and a musculoskeletal radiologist experienced in cartilage regeneration procedures in consensus.

\subsection{Statistical Methods}

All continuous data were expressed in terms of mean $\pm S D$, categorical variables were expressed as proportions or percentages. The Shapiro-Wilk test was performed to test normality of continuous variables. The Levene test was used to assess the homoscedasticity of the data. Repeated measures ANOVA was performed to compare the scores at different follow-up times. The one way ANOVA test was performed to assess the between group differences of continuous and normally distributed and homoscedastic data; the Mann-Whitney test was used otherwise. The Spearman rank correlation was used to assess correlations between numerical scores and continuous data, the Kendall's tau correlation was used to assess correlations between ordinal scores and continuous data. Pearson's chi square exact test was performed to investigate relationships between grouping variables. For all tests $p<0.05$ was considered significant. All statistical analysis was performed using SPSS v.19.0 (IBM Corp., Armonk, NY, USA).

\section{Results}

Both groups showed a marked improvement of all clinical scores from baseline to the last follow-up. The IKDC subjective score improved significantly in the mosaicplasty group from the basal level of $38.1 \pm 11.8$ to $75.3 \pm 21.8(\mathrm{p}<0.0005)$ at the final follow-up. Similarly, in the MACT group there was 
a significant improvement from the basal level of $37.6 \pm 14.9$ to the final follow-up of $81.8 \pm 13.0$ $(p<0.0005)$. No significant differences in the IKDC subjective scores were found between mosaicplasty and MACT groups (Figure 1).

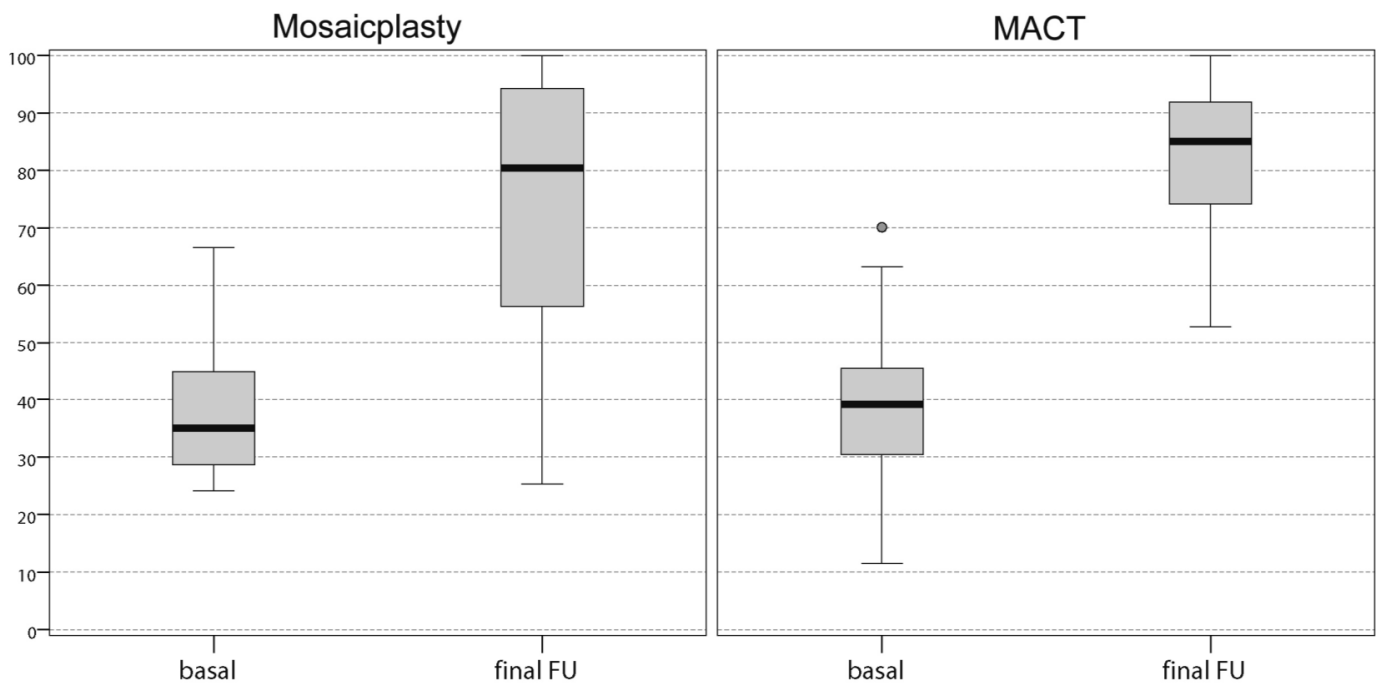

Figure 1. Comparison of the International Knee Documentation Committee (IKDC) subjective score achieved at a final follow-up of 12 years by both groups of patients. The values are expressed in median and 25th and 75th percentiles. No significant differences were found between the two groups. FU, follow-up.

The IKDC objective score in the mosaicplasty group improved from baseline, where no knees were evaluated as normal or nearly normal (13 C, $7 \mathrm{D})$, to 16 normal or nearly normal knees at 12 years of follow-up ( $7 \mathrm{~A}, 9 \mathrm{~B}, 3 \mathrm{C}, 1 \mathrm{D})$. In the MACT group, this score improved from 7 normal or nearly normal knees at baseline $(1 \mathrm{~A}, 6 \mathrm{~B}, 9 \mathrm{C}, 7 \mathrm{D})$ to 23 at the final follow-up (16 A, $7 \mathrm{~B})$. The IKDC objective score improvement was significantly higher in the MACT group compared with the mosaicplasty group at 12 years of follow-up $(\mathrm{p}=0.029)$. The Tegner score in the mosaicplasty group showed a significant improvement from $2.9 \pm 1.4$ at the pre-operative evaluation to $5.0 \pm 2.4$ at the final follow-up ( $\mathrm{p}=0.043$ ); however, the mean activity level remained lower vs. pre-injury $(7.1 \pm 2.0, \mathrm{p}=$ 0.081). Similarly, the Tegner score of the MACT group showed a statistically significant improvement $(\mathrm{p}=0.001)$ from the pre-operative level $(1.6 \pm 1.5)$ to the final follow-up $(5.3 \pm 2.1)$, although also in this case without reaching the pre-injury level $(7.0 \pm 1.6, p=0.081)$. No significant differences were found in the Tegner scores between mosaicplasty and MACT at the final follow-up, with only eight patients for each group achieving the pre-injury activity level 12 years after surgery (Figure 2).

Two patients of the mosaicplasty group failed (one with four plugs and one with three plugs) and were treated with MACT 2 years after the treatment, fixing a 10\% reoperation rate. At the final mean follow-up of 12 years, three more patients in the mosaicplasty group (one patient with one plug, one with two plugs, and one with four plugs) were considered clinical failures, for an overall failure rate of $25 \%$, significantly higher compared to the MACT group, where no surgical or clinical failures occurred $(\mathrm{p}=0.016)$.

The MRI findings of 30 knees (15 mosaicplasty and 15 MACT), analyzed with the MOCART 2.0 scoring system, showed a high rate of cartilage defect filling in both groups, and a complete integration into the adjacent cartilage in half of the patients in both groups. However, the surface of the repair tissue was damaged in the majority of cases. The structure of the repair tissue was homogeneous in most cases, and the signal intensity was normal (isointense) in half of the patients in both groups. At subchondral bone level, a bony defect or bony overgrowth was reported in the majority of patients, while an edema-like marrow signal was reported in almost half of the patients in both groups (Figures 3 
and 4). No significant differences were reported between the two groups in the overall MOCART 2.0 scores and in all the seven subscales (Table 2).

Further analysis was performed to determine the parameters that influenced the clinical outcome at the final follow-up in the two treatment groups. Defect size was found to significantly influence the final IKDC scores between the two groups, with MACT producing significantly higher objective results $(\mathrm{p}=0.031)$ and a tendency for higher subjective results compared to mosaicplasty $(81.8 \pm 18.3$ vs $58.8 \pm 25.0, \mathrm{p}=0.092$ ) for lesions $>2 \mathrm{~cm}^{2}$. Moreover, while size did not influence results in the MACT group, patients with lesions bigger than $2 \mathrm{~cm}^{2}$ had a lower improvement in their activity level as measured by Tegner $(\mathrm{p}=0.014)$ (Figure 5). Conversely, age, sex, BMI, site, etiology, number of plugs (for the mosaicplasty group), and previous or associated surgery did not significantly influence the final clinical outcome. No correlations were also found between MOCART 2.0 total scores or subscales and basal parameters, including age, BMI, and defect size. Moreover, no correlations were found between clinical scores (IKDC subjective and objective, and Tegner score) and MOCART 2.0 total scores or subscales at final follow-up.

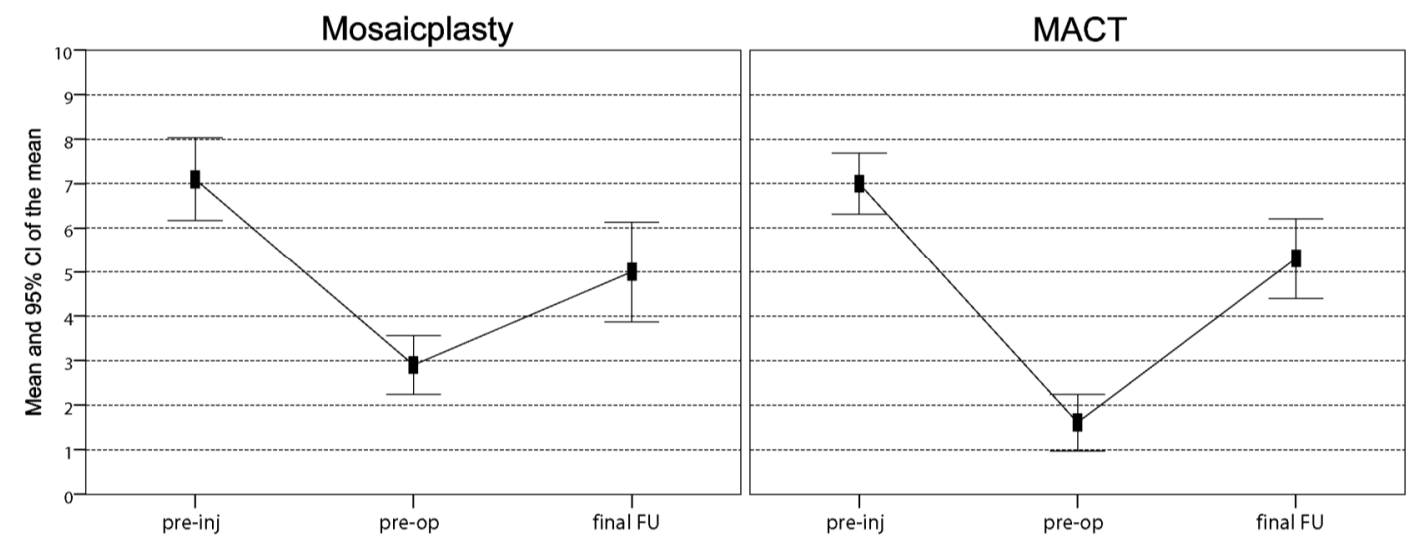

Figure 2. Comparison of the Tegner scores achieved at a final follow-up of 12 years. In both groups, scores improved significantly from the pre-operative level to the final follow-up, even though the mean activity level remained significantly lower vs. pre-injury. No differences were found in sports activity levels between the two groups. FU, follow-up; Pre-inj, pre-injury; Pre-op, pre-operative.
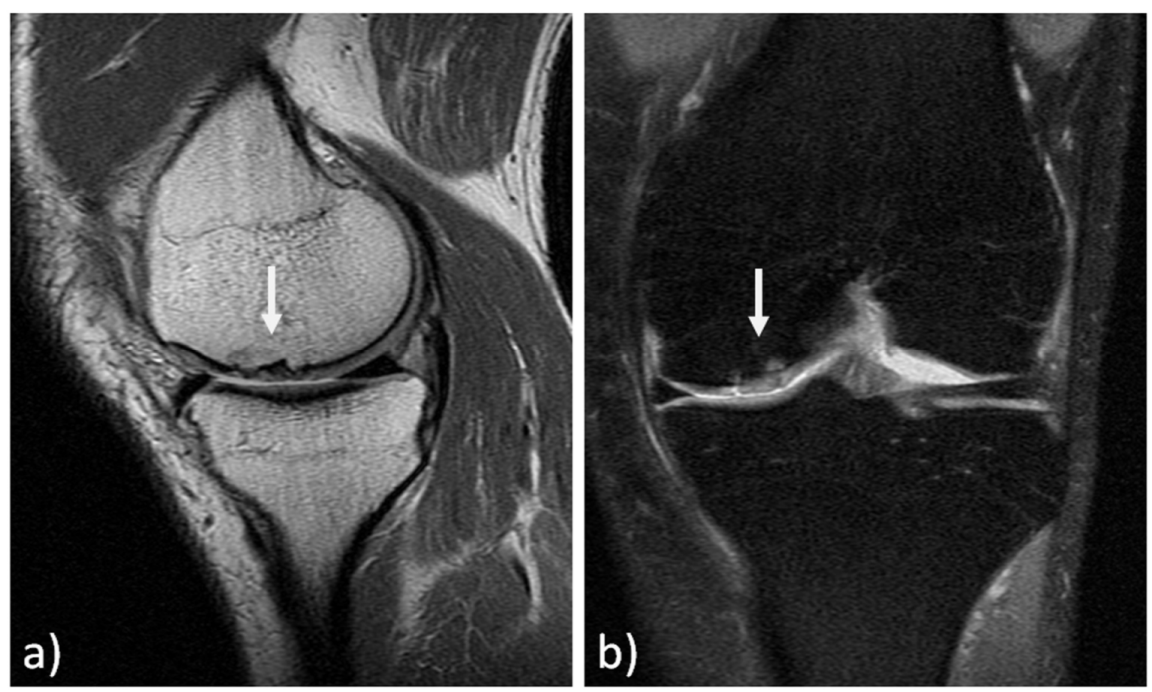

Figure 3. MRI evaluation at 11 years' follow-up of a medial femoral condyle lesion treated with mosaicplasty in a 37-year-old man. Sagittal 3D "Cube" PD (a) and coronal PD FAT SAT (b) demonstrate a good filling of the defect (arrows) and a complete integration into adjacent cartilage. However, there is an inhomogeneous structure of the repair tissue with adjacent bony overgrowth. 

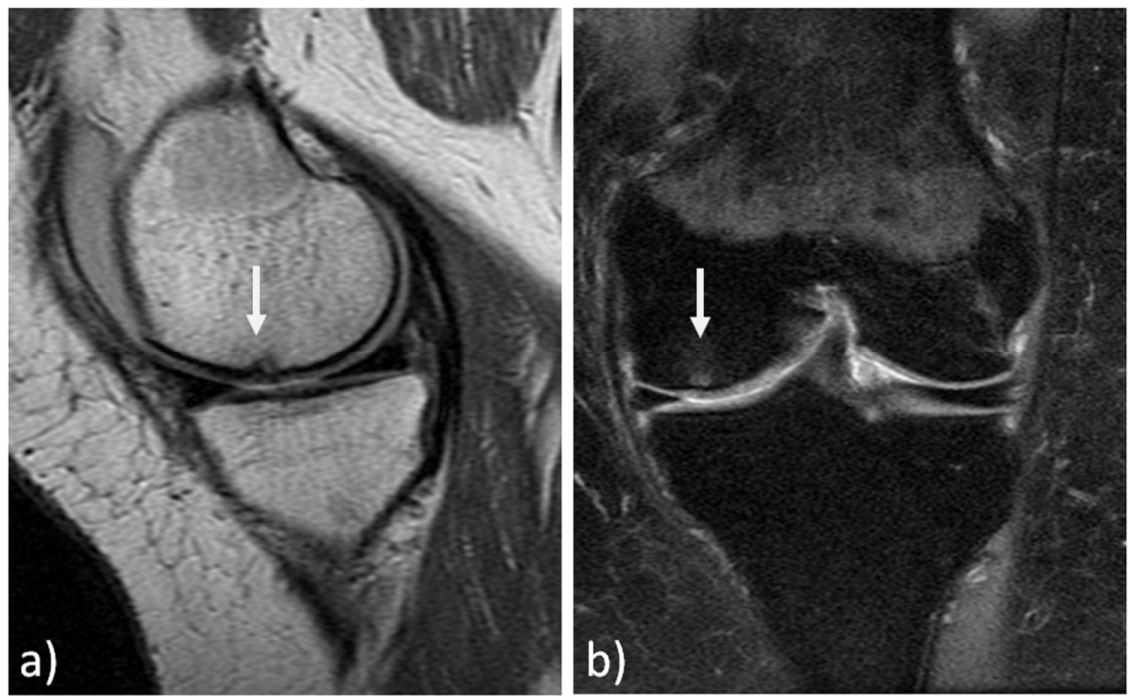

Figure 4. MRI evaluation at 9 years' follow-up of a medial femoral condyle lesion treated with matrix-assisted autologous chondrocyte transplantation in a 39-year-old woman. Sagittal 3D "Cube" PD (a) and coronal PD FAT SAT (b) demonstrate a good filling of the defect (arrows) and integration into adjacent cartilage, a homogeneous structure and a normal signal intensity of the repair tissue. Moreover, no significant bony defect, bony overgrowth, or major subchondral changes were detected.

Table 2. Magnetic resonance Observation of Cartilage Repair Tissue (MOCART) 2.0 evaluation.

\begin{tabular}{|c|c|c|c|c|c|}
\hline \multicolumn{3}{|c|}{ MOCART 2.0 Knee Score: Cartilage Repair Tissue Assessment } & $\begin{array}{c}\begin{array}{c}\text { Mosaicplasty } \\
\text { Group }\end{array} \\
4(26.7 \%)\end{array}$ & $\begin{array}{c}\text { MACT } \\
\text { Group } \\
4(26.7 \%)\end{array}$ & Comparison \\
\hline 1 & $\begin{array}{l}\text { Volume fill of } \\
\text { cartilage defect }\end{array}$ & $\begin{array}{l}\text { Complete filling or minor hypertrophy } \\
\text { Major hypertrophy ( } \geq 150 \% \text { ) or } 75 \% \text { to } 99 \% \text { filling } \\
50 \% \text { to } 74 \% \text { filling } \\
25 \% \text { to } 49 \% \text { filling } \\
<25 \% \text { filling or complete delamination in situ }\end{array}$ & $\begin{array}{c}4(26.7 \%) \\
6(40.0 \%) \\
4(26.7 \%) \\
1(6.6 \%) \\
0\end{array}$ & $\begin{array}{l}4(26.7 \%) \\
8(53.3 \%) \\
3(20.0 \%) \\
0 \\
0\end{array}$ & NS \\
\hline 2 & $\begin{array}{l}\text { Integration into } \\
\text { adjacent } \\
\text { cartilage }\end{array}$ & $\begin{array}{c}\text { Complete } \\
\text { Split-like defect } \leq 2 \mathrm{~mm} \\
\text { Defect }>2 \mathrm{~mm} \text { but }<50 \% \text { of repair tissue length } \\
\text { Defect } \geq 50 \% \text { of repair tissue length }\end{array}$ & $\begin{array}{l}8(53.3 \%) \\
3(20.0 \%) \\
4(26.7 \%) \\
0\end{array}$ & $\begin{array}{c}8(53.3 \%) \\
6(40.0 \%) \\
1(6.7 \%) \\
0\end{array}$ & NS \\
\hline 3 & $\begin{array}{l}\text { Surface of the } \\
\text { repair tissue }\end{array}$ & $\begin{array}{c}\text { Intact } \\
\text { Damaged: }<50 \% \text { of the repair tissue diameter } \\
\text { Damaged: } \geq 50 \% \text { of the repair tissue diameter }\end{array}$ & $\begin{array}{l}5(33.3 \%) \\
8(53.3 \%) \\
2(13.4 \%)\end{array}$ & $\begin{array}{c}3(20.0 \%) \\
10(66.6 \%) \\
2(13.4 \%)\end{array}$ & NS \\
\hline 4 & $\begin{array}{l}\text { Structure of the } \\
\text { repair tissue }\end{array}$ & $\begin{array}{l}\text { Homogeneous } \\
\text { Inhomogeneous }\end{array}$ & $\begin{array}{c}11(73.3 \%) \\
4(26.7 \%)\end{array}$ & $\begin{array}{c}10(66.7 \%) \\
5(33.3 \%)\end{array}$ & NS \\
\hline 5 & $\begin{array}{l}\text { Signal intensity } \\
\text { of the repair } \\
\text { tissue }\end{array}$ & $\begin{array}{c}\text { Normal } \\
\text { Minor abnormal: minor hyperintense or minor hypointense } \\
\text { Severely abnormal }\end{array}$ & $\begin{array}{c}7(46.7 \%) \\
7(46.7 \%) \\
1(6.6 \%)\end{array}$ & $\begin{array}{l}9(60.0 \%) \\
6(40.0 \%) \\
0\end{array}$ & NS \\
\hline 6 & $\begin{array}{c}\text { Bony defect or } \\
\text { bony } \\
\text { overgrowth }\end{array}$ & $\begin{array}{l}\text { No bony defect or bony overgrowth } \\
\text { Bony defect: depth }<\text { thickness of adjacent cartilage or } \\
\text { overgrowth }<50 \% \text { of adjacent cartilage } \\
\text { Bony defect: depth } \geq \text { thickness of adjacent cartilage or } \\
\text { overgrowth } \geq 50 \% \text { of adjacent cartilage }\end{array}$ & $\begin{array}{l}7(46.6 \%) \\
4(26.7 \%) \\
4(26.7 \%)\end{array}$ & $\begin{array}{l}5(33.3 \%) \\
9(60.0 \%) \\
1(6.7 \%)\end{array}$ & NS \\
\hline 7 & $\begin{array}{l}\text { Subchondral } \\
\text { changes }\end{array}$ & $\begin{array}{c}\text { No major subchondral changes } \\
\text { Minor edema-like marrow signal: maximum diameter }<50 \% \\
\text { of the repair tissue diameter } \\
\text { Severe edema-like marrow signal: maximum diameter } \geq 50 \% \\
\text { of the repair tissue diameter } \\
\text { Subchondral cysts } \geq 5 \mathrm{~mm} \text { or osteonecrosis-like signal }\end{array}$ & $\begin{array}{l}8(53.3 \%) \\
7(46.7 \%)\end{array}$ & $\begin{array}{l}8(53.3 \%) \\
4(26.7 \%) \\
3(20.0 \%) \\
0\end{array}$ & NS \\
\hline & $\begin{array}{l}\text { Total score, } \\
\text { mean } \pm \text { SD }\end{array}$ & - & $74.0 \pm 17.1$ & $\begin{array}{c}75.7 \pm \\
13.6\end{array}$ & NS \\
\hline
\end{tabular}

MACT, matrix-assisted autologous chondrocyte transplantation; MOCART, magnetic resonance observation of cartilage repair tissue; NS, not significant; SD, standard deviation. 


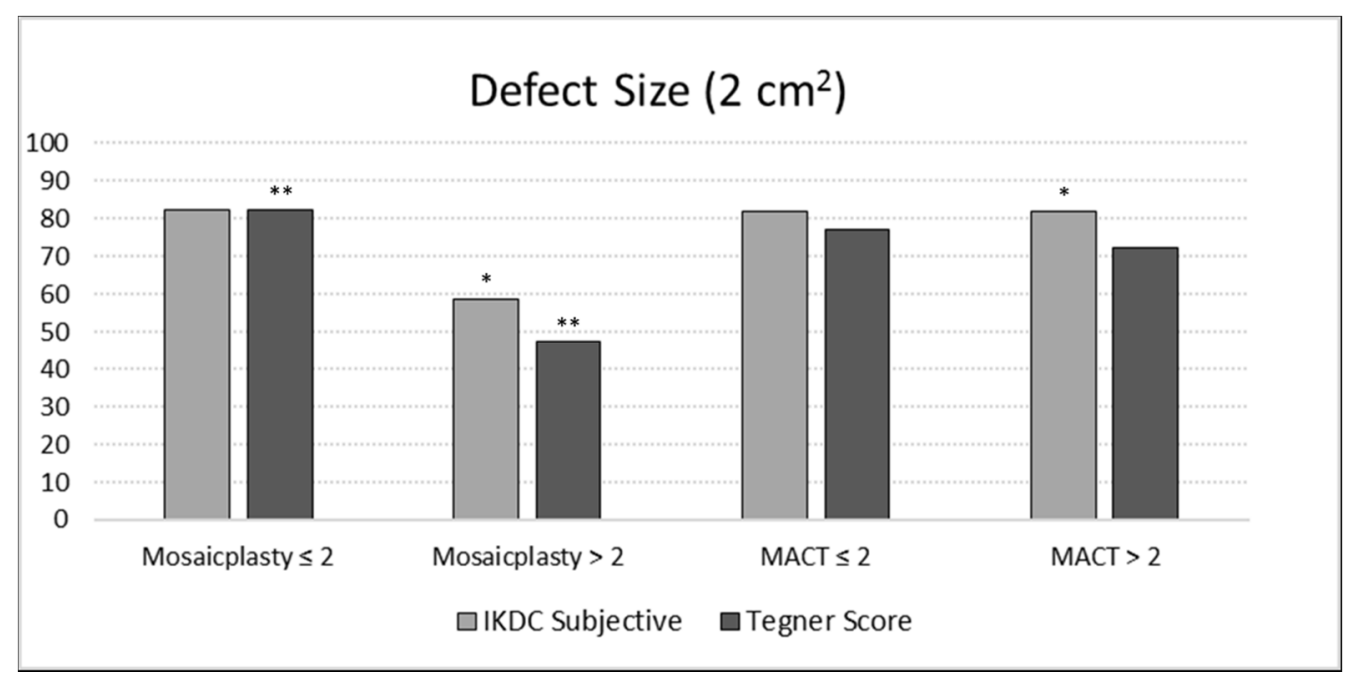

Figure 5. Evaluation of the defect size effect on the International Knee Documentation Committee (IKDC) subjective score and the percentage Tegner Score improvement at a final follow-up of 12 years in both groups of patients. The asterisk ${ }^{*}$ ) indicates for the MACT group a tendency for higher subjective results compared to the mosaicplasty group for the defect area $>2 \mathrm{~cm}^{2}(p=0.092)$. The double asterisk $(* *)$ indicates a lower improvement in terms of Tegner Score for the defect area $>2 \mathrm{~cm}^{2}$ in the mosaicplasty group $(\mathrm{p}=0.014)$.

\section{Discussion}

The main finding of this study is that both mosaicplasty and MACT techniques provided satisfactory clinical results at long-term follow-up in two homogeneous groups of patients affected by knee cartilage defects. Additionally, the MRI evaluation suggested a good and durable quality of repair tissue, although without correlations with the clinical outcomes. The comparative analysis of the two procedures suggested that while similar results were obtained for small lesions, MACT should be preferred versus mosaicplasty when addressing larger knee cartilage defects.

The overall clinical results reported in this study are in line with other recently published long-term studies, showing that both mosaicplasty and MACT may offer satisfactory and durable results when applied for the treatment of relatively small chondral lesions of knee femoral condyles [17,24-26]. In the largest available study of mosaicplasty that included 831 patients evaluated at 10 years of follow-up, Hangody et al. reported $92 \%$ good-to-excellent results with a low complication rate [26]. Similarly, Andriolo et al. performed a long-term evaluation at 15 years of follow-up in 113 patients treated with MACT, reporting a significant and stable clinical scores improvement. Even the failures rates reported in this study reflect the literature findings, with higher failure rates documented in patients treated with mosaicplasty technique compared to MACT. Pareek et al. [13] found that, at an average follow-up of 10 years, patients who underwent mosaicplasty had an overall failure rate of $28 \%$ and a reoperation rate of $19 \%$, thus reflecting the results obtained in the current study (overall failure rate of $25 \%$ and a reoperation rate of $10 \%$ ). The survival of MACT of the present study appears to be actually higher than previous findings. A systematic review reported a failure rate of $10.4 \%$ at mid-long term follow-up in patients treated with MACT [27]. However, these differences may be due to the different populations of patients considered; other studies demonstrated a higher failure rate in some patients categories, such as knee osteoarthritis and patellar defects $[25,28]$, and these types of patients were excluded in the current study, where no failures were documented in the MACT group.

Long-term results of both mosaicplasty and MACT have also been evaluated in comparison with other cartilage repair techniques. Compared to microfractures, mosaicplasty resulted in significantly better outcomes in several studies at long-term follow-up [29-31]. In particular, even though both mosaicplasty and microfractures presented a worsening of results at 10 years, Gudas et al. [32] reported significantly better results in patients treated with mosaicplasty, which presented a higher 
activity level, a lower failure rate, and a lower radiographic evidence of osteoarthritic degenerative progression. These results may be explained by the better quality of repair tissue provided by the use of autologous graft compared to fibrocartilage obtained with bone marrow stimulation techniques [32]. Similarly, MACT also presented better patient-reported outcome scores and lower failures compared to microfractures $[33,34]$. Additionally in this case, the excellent durability of MACT results could be explainable by the hyaline-like tissue restored [35], compared to the fibrocartilaginous repair tissue provided by microfractures as demonstrated by MRI studies [36,37].

The role of MRI in assessing cartilage repair tissue has been widely reported [38], and the imaging results of this study confirmed the literature findings in both treatment groups, with high MOCART 2.0 scores. However, several suboptimal imaging findings were also documented, both in terms of surface integrity and subchondral bone alterations, although these findings did not correlate with clinical results. To this regard, previous studies were controversial in regard the clinical significance of MRI findings. Tetta et al. [39] showed that mosaicplasty implants with a better imaging appearance also presented better objective and subjective scores, and Kon et al. [40] confirmed this correlation in patients treated with MACT. Conversely, Adrian et al. [41], while demonstrating a good-quality repair tissue at 10 years after MACT, found no correlation between clinical outcome and MRI results. These controversial findings have to be interpreted in light of a meta-analysis investigating the correlation between MRI and clinical outcomes after cartilage repair [42]. In fact, only $28 \%$ of the included studies found such correlation, leaving unanswered the question of whether MRI is reliable in predicting clinical outcomes after cartilage repair. Therefore, caution should be recommended when interpreting MRI findings and greater importance should be placed on the patient clinical evaluation. This is especially true in a comparative study such as the current one, aiming at determining the most suitable treatment in patients affected by cartilage lesions.

The present study compared both clinical and imaging outcomes of mosaicplasty and MACT at long-term follow-up. The results of these techniques in the literature, evaluated singularly, were confirmed, with good and long-lasting results and a low surgical failure rate. Mosaicplasty and MACT also showed similar overall clinical outcomes and comparable tissue repair quality at MRI evaluation. However, this comparative analysis underlined some interesting aspects. MACT presented better clinical results in relatively larger cartilage lesions, better objective findings, and a lower failure rate compared to mosaicplasty. These findings are inconsistent with the only available comparative analysis of these two techniques at short-term follow-up [19]. In detail, Clavé et al. reported a significantly greater symptom improvement 2 years after treatment for mosaicplasty compared to MACT in defects larger than $3.5 \mathrm{~cm}^{2}$, while no significant difference was found for smaller lesions [19]. On the other hand, in contrast to these results, Bentley et al. [43] reported a higher rate of failure in patients with large cartilage lesions treated with mosaicplasty compared to first-generation $\mathrm{ACI}$ at long-term follow-up, thus underlining that mosaicplasty is not a suitable option for the treatment of large lesions. This result was confirmed by other authors that investigated the significance of the lesion size for mosaicplasty technique, showing better clinical improvement in patients affected by small lesions $[44,45]$. An important aspect related to the lesion size is the number of plugs used to cover the defect being correlated with the clinical outcomes and the failure rate [45]. A limited number of plugs could correlate with better results probably because of the cylindrical shape of the grafts that does not allow optimal coverage of the lesion site by multiple grafts, leaving residual small uncovered areas that might impair or diminish the healing process $[46,47]$.

Another important aspect that needs to be taken into account when evaluating cartilage procedures is the clinical profiling, aimed at determining the patient and lesion characteristics which may play a prognostic role on the final outcome [48]. Many studies evaluated several factors that can influence the failure rate of both these techniques. Among them, age, sex, etiology and size of the defect seem to modify the failure rate, with female patients, older patients and those affected by degenerative or larger lesions, complex cases, and patients undergoing salvage treatment being more at risk of failures $[13,24,25,49,50]$. Such profiling of patient characteristics which may influence the outcome 
were not possible in this series due to the low number of patients, although interesting findings could be underlined for the most suitable treatment indication based on the lesion size.

The current study has limitations that should be considered in the interpretation of the results. First of all, the retrospective design, with consequent lack of randomization, may entail an inclusion bias, with different patients treated with different procedures. Nevertheless, data were collected prospectively, and the strict patient selection by a statistician blinded to the study outcome allowed us to obtain two homogeneous groups to compare, thus allowing us to draw conclusions about the selected population. The absence of an intermediate evaluation is another limitation. Unfortunately, some patients of the two treatment groups were not evaluated at the intermediate follow-ups, hindering the possibility to better understand possible oscillations of the outcomes over time between the two techniques. Nevertheless, short and mid-term follow-ups of both procedures have already been reported in the literature. Secondarily, the relatively small number of patients evaluated hindered the possibility to confirm some correlations between outcome and influencing factors. Moreover, a slight (although not significant) heterogeneity was present between the two groups in terms of etiology, with some more degenerative cases in the mosaicplasty group. Nevertheless, the current survey represents the largest population evaluated in a comparative long-term analysis, and allowed meaningful clinical and MRI results, showing overall good results over time for both techniques, but lower results for mosaicplasty in lesions larger than $2 \mathrm{~cm}^{2}$. Other limitations are the absence of arthroscopic and histologic examinations, and of a radiologic follow-up, often considered the ideal technique for evaluating cartilage quality and OA evolution. Moreover, the imaging evaluation was not available for all patients, because some patients declined to undergo MRI exam. Nevertheless, the high rate of MRI evaluations at long-term follow-up and the use of the recent MOCART 2.0 tool offered important information regarding the state of the repair tissue and of the whole joint, leaving the analysis of the degenerative progression to future studies with longer follow-up times.

Alternative solutions have been explored to restore the articular surface while overcoming the drawbacks of mosaicplasty and MACT, aiming at lowering costs, simplifying the procedure, and improving long-term results [51,52]. The most recent developments involve the use of cell sources for one-step solutions or the application of biomaterials, such as a cell-free approach [53-56]. Nevertheless, while research is moving forward, it is fundamental to keep documenting the results of the most established procedures like mosaicplasty and MACT, to better understand how much and how long can patients benefit from these cartilage procedures, to detect the ideal candidates through a patient profiling, and to set a reference point to measure the potential of the other emerging solutions.

Author Contributions: Conceptualization, S.Z. and G.F.; methodology, M.B. and A.D.M.; data curation, D.R.; writing-original draft preparation, A.B. and L.A.; writing-review and editing, G.F.; supervision, A.D.M., M.B., G.F., and S.Z. All authors have read and agreed to the published version of the manuscript.

Funding: This research received no external funding.

Conflicts of Interest: S.Z. has received institutional support from Fidia Farmaceutici, Cartiheal, IGEA Clinical Biophysics, Biomet, and Kensey Nash; grant support from I+; and royalties from Springer. The funders had no role in the design of the study; in the collection, analyses, or interpretation of data; in the writing of the manuscript, or in the decision to publish the results. The other authors declare no conflict of interest.

\section{References}

1. Everhart, J.S.; Campbell, A.B.; Abouljoud, M.M.; Kirven, J.C.; Flanigan, D.C. Cost-efficacy of knee cartilage defect treatments in the United States. Am. J. Sports Med. 2020, 48, 242-251. [CrossRef] [PubMed]

2. Chubinskaya, S.; Haudenschild, D.; Gasser, S.; Stannard, J.; Krettek, C.; Borrelli, J., Jr. Articular cartilage injury and potential remedies. J. Orthop. Trauma 2015, 29, 47-52. [CrossRef] [PubMed]

3. Filardo, G.; Kon, E.; Roffi, A.; Di Martino, A.; Marcacci, M. Scaffold-based repair for cartilage healing: A systematic review and technical note. Arthroscopy 2013, 29, 174-186. [CrossRef] [PubMed]

4. Ambra, L.F.; de Girolamo, L.; Mosier, B.; Gomoll, A.H. Review: Interventions for Cartilage Disease: Current State-of-the-Art and Emerging Technologies. Arthritis Rheumatol. 2017, 69, 1363-1373. [CrossRef] 
5. Heijink, A.; Gomoll, A.H.; Madry, H.; Drobnic, M.; Filardo, G.; Espregueira-Mendes, J.; Van Dijk, C.N. Biomechanical considerations in the pathogenesis of osteoarthritis of the knee. Knee Surg. Sports Traumatol. Arthrosc. 2012, 20, 423-435. [CrossRef]

6. Davies-Tuck, M.L.; Wluka, A.E.; Wang, Y.; Teichtahl, A.J.; Jones, G.; Ding, C.; Cicuttini, F.M. The natural history of cartilage defects in people with knee osteoarthritis. Osteoarthr. Cartil. 2008, 16, 337-342. [CrossRef] [PubMed]

7. Richter, D.L.; Schenck, R.C., Jr.; Wascher, D.C.; Treme, G. Knee articular cartilage repair and restoration techniques: A review of the literature. Sports Health 2016, 8, 153-160. [CrossRef]

8. Yamashita, F.; Sakakida, K.; Suzu, F.; Takai, S. The transplantation of an autogeneic osteochondral fragment for osteochondritis dissecans of the knee. Clin. Orthop. Relat. Res. 1985, 201, 43-50. [CrossRef]

9. Brittberg, M.; Lindahl, A.; Nilsson, A.; Ohlsson, C.; Isaksson, O.; Peterson, L. Treatment of deep cartilage defects in the knee with autologous chondrocyte transplantation. N. Engl. J. Med. 1994, 331, 889-895. [CrossRef]

10. Andrade, R.; Vasta, S.; Pereira, R.; Pereira, H.; Papalia, R.; Karahan, M.; Oliveira, J.M.; Reis, R.L.; Espregueira-Mendes, J. Knee donor-site morbidity after mosaicplasty-A systematic review. J. Exp. Orthop. 2016, 3, 31. [CrossRef]

11. Minas, T. Autologous chondrocyte implantation for focal chondral defects of the knee. Clin. Orthop. Relat. Res. 2001, 391, 349-361. [CrossRef]

12. Kon, E.; Verdonk, P.; Condello, V.; Delcogliano, M.; Dhollander, A.; Filardo, G.; Pignotti, E.; Marcacci, M. Matrix-assisted autologous chondrocyte transplantation for the repair of cartilage defects of the knee: systematic clinical data review and study quality analysis. Am. J. Sports Med. 2009, 37, 156-166. [CrossRef] [PubMed]

13. Pareek, A.; Reardon, P.J.; Maak, T.G.; Levy, B.A.; Stuart, M.J.; Krych, A.J. Long-term outcomes after osteochondral autograft transfer: A systematic review at mean follow-up of 10.2 years. Arthroscopy 2016, 32, 1174-1184. [CrossRef] [PubMed]

14. Hangody, L.; Kish, G.; Karpati, Z.; Szerb, I.; Udvarhelyi, I. Arthroscopic autogenous osteochondral mosaicplasty for the treatment of femoral condylar articular defects A preliminary report. Knee Surg. Sports Traumatol. Arthrosc. 1997, 5, 262-267. [CrossRef] [PubMed]

15. Kon, E.; Delcogliano, M.; Filardo, G.; Montaperto, C.; Marcacci, M. Second generation issues in cartilage repair. Sports Med. Arthrosc. Rev. 2008, 16, 221-229. [CrossRef]

16. Cortese, F.; McNicholas, M.; Janes, G.; Gillogly, S.; Abelow, S.P.; Gigante, A.; Coletti, N. Arthroscopic Delivery of Matrix-Induced Autologous Chondrocyte Implant: International Experience and Technique Recommendations. Cartilage 2012, 3, 156-164. [CrossRef]

17. Solheim, E.; Hegna, J.; Oyen, J.; Harlem, T.; Strand, T. Results at 10 to 14 years after osteochondral autografting (mosaicplasty) in articular cartilage defects in the knee. Knee 2013, 20, 287-290. [CrossRef]

18. Zaffagnini, S.; Vannini, F.; Di Martino, A.; Andriolo, L.; Sessa, A.; Perdisa, F.; Balboni, F.; Filardo, G. Low rate of return to pre-injury sport level in athletes after cartilage surgery: A 10-year follow-up study. Knee Surg. Sports Traumatol. Arthrosc. 2019, 27, 2502-2510. [CrossRef]

19. Clave, A.; Potel, J.F.; Servien, E.; Neyret, P.; Dubrana, F.; Stindel, E. Third-generation autologous chondrocyte implantation versus mosaicplasty for knee cartilage injury: 2-year randomized trial. J. Orthop. Res. 2016, 34, 658-665. [CrossRef]

20. Filardo, G.; Kon, E.; Perdisa, F.; Tetta, C.; Di Martino, A.; Marcacci, M. Arthroscopic mosaicplasty: Long-term outcome and joint degeneration progression. Knee 2015, 22, 36-40. [CrossRef]

21. Filardo, G.; Kon, E.; Di Martino, A.; Patella, S.; Altadonna, G.; Balboni, F.; Bragonzoni, L.; Visani, A.; Marcacci, M. Second-generation arthroscopic autologous chondrocyte implantation for the treatment of degenerative cartilage lesions. Knee Surg. Sports Traumatol. Arthrosc. 2012, 20, 1704-1713. [CrossRef] [PubMed]

22. Filardo, G.; Andriolo, L.; Balboni, F.; Marcacci, M.; Kon, E. Cartilage failures. Systematic literature review, critical survey analysis, and definition. Knee Surg. Sports Traumatol. Arthrosc. 2015, 23, 3660-3669. [CrossRef]

23. Schreiner, M.M.; Raudner, M.; Marlovits, S.; Bohndorf, K.; Weber, M.; Zalaudek, M.; Rohrich, S.; Szomolanyi, P.; Filardo, G.; Windhager, R.; et al. The MOCART (Magnetic Resonance Observation of Cartilage Repair Tissue) 2.0 Knee Score and Atlas. Cartilage 2019. [CrossRef] [PubMed] 
24. Brix, M.O.; Stelzeneder, D.; Chiari, C.; Koller, U.; Nehrer, S.; Dorotka, R.; Windhager, R.; Domayer, S.E. Treatment of Full-Thickness Chondral Defects with Hyalograft C in the Knee: Long-term Results. Am. J. Sports Med. 2014, 42, 1426-1432. [CrossRef] [PubMed]

25. Andriolo, L.; Reale, D.; Di Martino, A.; Zaffagnini, S.; Vannini, F.; Ferruzzi, A.; Filardo, G. High rate of failure after matrix-assisted autologous chondrocyte transplantation in osteoarthritic knees at 15 years of follow-up. Am. J. Sports Med. 2019, 47, 2116-2122. [CrossRef]

26. Hangody, L.; Fules, P. Autologous osteochondral mosaicplasty for the treatment of full-thickness defects of weight-bearing joints: Ten years of experimental and clinical experience. J. Bone Jt. Surg. Am. 2003, 85, 25-32. [CrossRef]

27. Andriolo, L.; Merli, G.; Filardo, G.; Marcacci, M.; Kon, E. Failure of autologous chondrocyte implantation. Sports Med. Arthrosc. Rev. 2017, 25, 10-18. [CrossRef]

28. Kon, E.; Filardo, G.; Gobbi, A.; Berruto, M.; Andriolo, L.; Ferrua, P.; Crespiatico, I.; Marcacci, M. Long-term results after hyaluronan-based MACT for the treatment of cartilage lesions of the patellofemoral joint. Am. J. Sports Med. 2016, 44, 602-608. [CrossRef]

29. Solheim, E.; Hegna, J.; Inderhaug, E. Long-term clinical follow-up of microfracture versus mosaicplasty in articular cartilage defects of medial femoral condyle. Knee 2017, 24, 1402-1407. [CrossRef]

30. Solheim, E.; Hegna, J.; Inderhaug, E. Long-term survival after microfracture and mosaicplasty for knee articular cartilage repair: A comparative study between two treatments cohorts. Cartilage 2020, 11, 71-76. [CrossRef]

31. Solheim, E.; Hegna, J.; Strand, T.; Harlem, T.; Inderhaug, E. Randomized study of long-term (15-17 years) outcome after microfracture versus mosaicplasty in knee articular cartilage defects. Am. J. Sports Med. 2018, 46, 826-831. [CrossRef] [PubMed]

32. Gudas, R.; Gudaite, A.; Pocius, A.; Gudiene, A.; Cekanauskas, E.; Monastyreckiene, E.; Basevicius, A. Ten-year follow-up of a prospective, randomized clinical study of mosaic osteochondral autologous transplantation versus microfracture for the treatment of osteochondral defects in the knee joint of athletes. Am. J. Sports Med. 2012, 40, 2499-2508. [CrossRef]

33. Kon, E.; Gobbi, A.; Filardo, G.; Delcogliano, M.; Zaffagnini, S.; Marcacci, M. Arthroscopic second-generation autologous chondrocyte implantation compared with microfracture for chondral lesions of the knee: Prospective nonrandomized study at 5 years. Am. J. Sports Med. 2009, 37, 33-41. [CrossRef] [PubMed]

34. Everhart, J.S.; Jiang, E.X.; Poland, S.G.; Du, A.; Flanigan, D.C. Failures, reoperations, and improvement in knee symptoms following matrix-assisted autologous chondrocyte transplantation: A meta-analysis of prospective comparative trials. Cartilage 2019. [CrossRef] [PubMed]

35. Brittberg, M.; Peterson, L.; Sjogren-Jansson, E.; Tallheden, T.; Lindahl, A. Articular cartilage engineering with autologous chondrocyte transplantation. A review of recent developments. J. Bone Jt. Surg. Am. 2003, 85, 109-115. [CrossRef] [PubMed]

36. Mithoefer, K.; McAdams, T.; Williams, R.J.; Kreuz, P.C.; Mandelbaum, B.R. Clinical efficacy of the microfracture technique for articular cartilage repair in the knee: An evidence-based systematic analysis. Am. J. Sports Med. 2009, 37, 2053-2063. [CrossRef]

37. Domayer, S.E.; Kutscha-Lissberg, F.; Welsch, G.; Dorotka, R.; Nehrer, S.; Gabler, C.; Mamisch, T.C.; Trattnig, S. T2 mapping in the knee after microfracture at 3.0 T: Correlation of global T2 values and clinical outcome-preliminary results. Osteoarthr. Cartil. 2008, 16, 903-908. [CrossRef]

38. Liu, Y.W.; Tran, M.D.; Skalski, M.R.; Patel, D.B.; White, E.A.; Tomasian, A.; Gross, J.S.; Vangsness, C.T.; Matcuk, G.R., Jr. MR imaging of cartilage repair surgery of the knee. Clin. Imaging 2019, 58, 129-139. [CrossRef]

39. Tetta, C.; Busacca, M.; Moio, A.; Rinaldi, R.; Delcogliano, M.; Kon, E.; Filardo, G.; Marcacci, M.; Albisinni, U. Knee osteochondral autologous transplantation: Long-term MR findings and clinical correlations. Eur. J. Radiol. 2010, 76, 117-123. [CrossRef]

40. Kon, E.; Di Martino, A.; Filardo, G.; Tetta, C.; Busacca, M.; Iacono, F.; Delcogliano, M.; Albisinni, U.; Marcacci, M. Second-generation autologous chondrocyte transplantation: MRI findings and clinical correlations at a minimum 5-year follow-up. Eur. J. Radiol. 2011, 79, 382-388. [CrossRef]

41. Aldrian, S.; Zak, L.; Wondrasch, B.; Albrecht, C.; Stelzeneder, B.; Binder, H.; Kovar, F.; Trattnig, S.; Marlovits, S. Clinical and radiological long-term outcomes after matrix-induced autologous chondrocyte transplantation: A prospective follow-up at a minimum of 10 years. Am. J. Sports Med. 2014, 42, 2680-2688. [CrossRef] 
42. Windt, d.T.S.; Welsch, G.H.; Brittberg, M.; Vonk, L.A.; Marlovits, S.; Trattnig, S.; Saris, D.B. Is magnetic resonance imaging reliable in predicting clinical outcome after articular cartilage repair of the knee? A systematic review and meta-analysis. Am. J. Sports Med. 2013, 41, 1695-1702. [CrossRef] [PubMed]

43. Bentley, G.; Biant, L.C.; Vijayan, S.; Macmull, S.; Skinner, J.A.; Carrington, R.W. Minimum ten-year results of a prospective randomised study of autologous chondrocyte implantation versus mosaicplasty for symptomatic articular cartilage lesions of the knee. J. Bone Jt. Surg. Br. 2012, 94, 504-509. [CrossRef] [PubMed]

44. Marcacci, M.; Kon, E.; Delcogliano, M.; Filardo, G.; Busacca, M.; Zaffagnini, S. Arthroscopic autologous osteochondral grafting for cartilage defects of the knee: Prospective study results at a minimum 7-year follow-up. Am. J. Sports Med. 2007, 35, 2014-2021. [CrossRef]

45. Ollat, D.; Lebel, B.; Thaunat, M.; Jones, D.; Mainard, L.; Dubrana, F.; Versier, G. Mosaic osteochondral transplantations in the knee joint, midterm results of the SFA multicenter study. Orthop. Traumatol. Surg. Res. 2011, 97, 160-166. [CrossRef]

46. Hangody, L.; Kish, G.; Karpati, Z.; Udvarhelyi, I.; Szigeti, I.; Bely, M. Mosaicplasty for the treatment of articular cartilage defects: Application in clinical practice. Orthopedics 1998, 21, 751-756. [CrossRef] [PubMed]

47. Filardo, G.; Kon, E.; Di Matteo, B.; Di Martino, A.; Marcacci, M. Single-plug autologous osteochondral transplantation: Results at minimum 16 years' follow-up. Orthopedics 2014, 37, e761-e767. [CrossRef]

48. Filardo, G.; Kon, E.; Andriolo, L.; Di Matteo, B.; Balboni, F.; Marcacci, M. Clinical profiling in cartilage regeneration: Prognostic factors for midterm results of matrix-assisted autologous chondrocyte transplantation. Am. J. Sports Med. 2014, 42, 898-905. [CrossRef]

49. Filardo, G.; Kon, E.; Andriolo, L.; Vannini, F.; Buda, R.; Ferruzzi, A.; Giannini, S.; Marcacci, M. Does patient sex influence cartilage surgery outcome? Analysis of results at 5-year follow-up in a large cohort of patients treated with Matrix-assisted autologous chondrocyte transplantation. Am. J. Sports Med. 2013, 41, 1827-1834. [CrossRef]

50. Pareek, A.; Carey, J.L.; Reardon, P.J.; Peterson, L.; Stuart, M.J.; Krych, A.J. Long-term outcomes after autologous chondrocyte implantation: A systematic review at mean follow-up of 11.4 years. Cartilage 2016, 7, 298-308. [CrossRef]

51. Dhollander, A.A.; Guevara Sanchez, V.R.; Almqvist, K.F.; Verdonk, R.; Verbruggen, G.; Verdonk, P.C. The use of scaffolds in the treatment of osteochondral lesions in the knee: Current concepts and future trends. J. Knee Surg. 2012, 25, 179-186. [CrossRef]

52. Filardo, G.; Andriolo, L.; Angele, P.; Berruto, M.; Brittberg, M.; Condello, V.; Chubinskaya, S.; Girolamo, d.L.; Di Martino, A.; Di Matteo, B.; et al. Scaffolds for Knee Chondral and Osteochondral Defects: Indications for Different Clinical Scenarios. A Consensus Statement. Cartilage 2020. [CrossRef] [PubMed]

53. Gobbi, A.; Whyte, G.P. Long-term clinical outcomes of one-stage cartilage repair in the knee with hyaluronic acid-based scaffold embedded with mesenchymal stem cells sourced from bone marrow aspirate concentrate. Am. J. Sports Med. 2019, 47, 1621-1628. [CrossRef] [PubMed]

54. Yamagata, K.; Nakayamada, S.; Tanaka, Y. Use of mesenchymal stem cells seeded on the scaffold in articular cartilage repair. Inflamm. Regen. 2018, 38, 4. [CrossRef] [PubMed]

55. Boffa, A.; Previtali, D.; Altamura, S.A.; Zaffagnini, S.; Candrian, C.; Filardo, G. Platelet-Rich Plasma Augmentation to Microfracture Provides a Limited Benefit for the Treatment of Cartilage Lesions: A Meta-analysis. Orthop. J. Sports Med. 2020, 8, 2325967120910504. [CrossRef] [PubMed]

56. Andriolo, L.; Reale, D.; Di Martino, A.; Boffa, A.; Zaffagnini, S.; Filardo, G. Cell-free scaffolds in cartilage knee surgery: A systematic review and meta-analysis of clinical evidence. Cartilage 2019. [CrossRef] [PubMed]

(C) 2020 by the authors. Licensee MDPI, Basel, Switzerland. This article is an open access article distributed under the terms and conditions of the Creative Commons Attribution (CC BY) license (http://creativecommons.org/licenses/by/4.0/). 